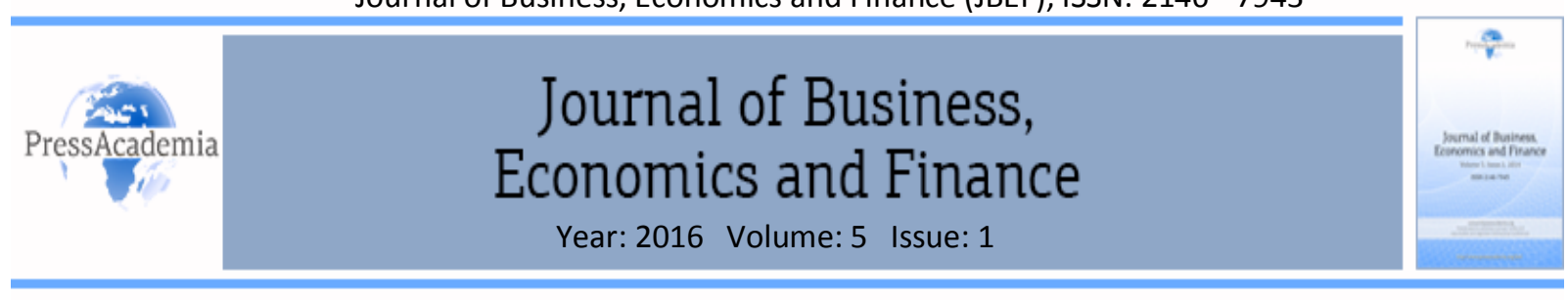

\title{
THE EFFECTS OF COGNITION AND AFFECT BASED TRUST ON ORGANIZATION IDENTIFICATION
}

\section{DOI: 10.17261/Pressacademia.2016116554}

\author{
Hasim Cuce ${ }^{1}$, Ozge Tayfur Ekmekci ${ }^{2}$, Semra Guney ${ }^{3}$ \\ ${ }^{1}$ Turkish Armed Forces. hasimmm293@hotmail.com \\ ${ }^{2}$ Hacettepe University. otayfur@hacettepe.edu.tr \\ ${ }^{3}$ Hacettepe University. semguney@yahoo.com
}

\begin{abstract}
This study aims to investigate the effects of cognition and affect-based trust on organizational identification and test whether the predictive power of these two trust dimensions differs for male and female employees. Data were collected from 161 white-collar employees of a Turkish public organization. The results of path analysis did not support the hypotheses indicating that affect and cognitionbased trust positively predicted organizational identification. However, the effects of affect and cognition-based trust on identification were found to be significant after controlling the effects of demographic variables and social desirability. In multi-group path analysis, the differential effect of gender was not found to be significant. That is, the effects of affect and cognition-based trust on identification were not stronger for women and men employees respectively. Despite the insignificant effects of trust dimensions, this study demonstrated the importance of overall supervisory trust on the development of identification. In line with Social Exchange Theory, employees tend to reciprocate their supervisors' trustworthiness by being identified with their organization. Alternatively, employees may feel identification because existence of trustworthy supervisors within the organization could help them to portray good image to both themselves and other people.
\end{abstract}

Key words: Supervisory-trust, cognition-based trust, affect-based trust, identification, gender. JEL Classification: M10, M12, M54

\section{INTRODUCTION}

Lifelong employment becomes an exception and employee loyalty substantially diminishes in today's business world. Mergers, takeovers and restructurings turn out to be part of business life and redefine the employee and organization relations. As the threats to employee loyalty increases, retaining talented employees and eliciting their identification with the organization has gained importance for the effectiveness of organizations and for the well-being of their members. Identification, which reflects "employees' perception of oneness with or belongingness to the organization" (Ashforth \& Mael, 1989, p.21) may increase employees' performance, decrease their desire for leaving the organization and make them more committed to their job and organization (Kreiner \& Ashforth, 2004). Anticipating these positive consequences, many researchers directed their attention to find the correlates and antecedents of organizational identification. Regarded as the basis of any quality relationships, trust seems to be one of most prominent antecedents of identification.

Besides enhancing relationships and identification, today's complex and ambiguous business environment calls for more collaboration and coordination between supervisors and employees. Effective execution of the tasks and gaining competitive advantage largely depend on interpersonal trust established between supervisors and employees. Supervisory trust, which is related to employees' willingness to rely on their supervisor(s) and 
expectations of regular, honest, and cooperative behavior from them" (Doney, Cannon \& Mullen, 1998; Fukuyama, 1995) results in number of positive work outcomes such as enhanced team (Dirks, 2000) and organizational performance (Davis, Schoorman, Mayer, \& Tan, 2000), reduced turnover intention (Mulki, Jaramillo \& Locander, 2006) and organizational citizenship behaviors (McAllister, 1995).

Despite the extensive and well-developed literature on organizational identification and supervisory trust, relatively few studies (e.g., DeConnick, 2011) addressed the relationship between these constructs. This study aims to investigate seemingly under-explored relationship by examining the effects of affect and cognitionbased trust on identification. The study distinguishes itself from many studies: a) by testing the effects of both affect and cognition-based trust on identification rather than testing the effect of supervisory trust in general, b) by testing the relationship between supervisory trust and organizational identification separately for female and male employees to understand whether gender influences that relationship. We believe that understanding how supervisor trust affects employees' level of identification would contribute to existing literature because much of the research has been conducted primarily in individualistic cultures, not in collectivist cultures. This shortcoming raises questions about the generalizability of the results to collectivist cultures, typical of Eastern societies. Collectivist cultures stresses the importance of relatedness, community and expressive ties, which could shape the exchanges among employees, supervisors and organizations in an unpredictable or different way compared to individualistic cultures. Being conducted in Turkey characterized with relatively collectivistic culture (Hofstede, 1980), this study could contribute the existing literature by revealing the motivational underpinning of organizational identification.

\section{LITERATURE REVIEW}

\subsection{Organization Identification}

Despite the voluminous number of research, there seems to be lack of agreement regarding the definition of organizational identification. Although some researchers (e.g., Hall, Schneider, \& Nygren, 1970; Pratt, 1998; Stengel, 1987) conceptualize identification as a cognitive construct, others (e.g., O'Reilly and Chatman, 1986) define and conceptualize it by giving reference to affective-motivational terms. The researchers following the first approach (cognition approach) generally define identification by drawing attention to perceived similarity between organization and self-identity. For example, Stengel (1987, p.175) defines organizational identification as a process whereby an individual's beliefs about organization become self-referential or self-defining. Dutton, Dukerich and Harquail (1994) gave a similar definition such that "identification is a process of incorporating the perception of oneself as a member of a particular organization into one's general self-definition. Having a different focus, first Kelman (1961), then O'Reilly and Chatman (1986) stresses affective-motivational side of identification by giving reference to desires and attraction. According to Kelman (1961) identification develops when an individual accepts the influence of others to establish or maintain a satisfying relationship. Thanks to identification, individual feels proud to be a part of group and respect its values and accomplishments.

Today, the concept of organizational identification is explained mostly with "Social Identity" theory, which incorporates both cognitive and affective terms. The theory simply proposes that individual's self-concept partly derives from his [or her] knowledge of his [or her] membership of a group (or groups) together with the value and emotional significance attached to that membership" (Tajfel, 1978, p. 63). Accordingly, if an individual conceives of himself or herself in terms of the membership of a group, that is, if $s /$ he identifies with the group, his/her self-concept, attitudes and behaviors are governed by this group membership (Deaux, 1996). Defining it as "employees' perception of oneness with or belongingness to the organization" (Tolman, 1943, cited in Mael \& Ashforth, 2001), Ashforth and Mael (1989; 2001) accept organizational identification as 'a specific form of social identification'. Through identification, the organization provides the employees with a sense of identity; as a result, employees take the organization's perspective and act in the organization's best interest. As Riketta (2005) points out all definitions share similarity despite the different phrases and words utilized. These definitions suggest that through identification the employees seem to associate his or her organizational membership with his or her self-concept, either cognitively (e.g., feeling a part of the organization; internalizing organizational values), emotionally (pride in membership), or both (Riketta, 2005). In 
this study, we will adopt the definition of Ashforth and Mael (1989) and regard identification as "perception of belongingness to a group and a sense of oneness with the group" (p.21).

Despite the lack of agreement about the definition of identification, there is no doubt that the concept of identification is important for organizations because it explains interpersonal relations (why employees prefer interacting with others in a particular way), work values (i.e., why employees approach their work the way they do) and reasons for joining or leaving the organization (DeConnick, 2011).

\subsection{Trust \& Supervisory-Trust}

Trust was found to be associated with different organizational outcomes such as reduced transaction costs, improved inter organizational and manager-subordinate relationships (Doney, Cannon \& Mullen, 1998), and increased job satisfaction, organizational commitment and job performance (Dirks \& Ferrin, 2001). Despite the voluminous number of research about its consequences, there is no agreed upon definition of trust. Some researchers (e.g., Axelrod, 1984; Deutsch, 1960; cited in Lewicki, Tomlinson \& Gillespie, 2006) define trust by giving reference to people's behaviors whereas others define it by means of expectations, intentions, affect and dispositions (e.g., Mayer et al., 1995, Fukuyama, 1995). Focusing on behaviors, Deutsch (1962) defines trust as "actions that increase one's vulnerability to another" (p.276). Accordingly, the trustor must decide how much to cooperate with the trustee and his/her level of trust is inferred from the level and frequency of cooperative behaviors shown (Lewicki et al., 2006). Focusing on expectations, intentions, affect and dispositions, Fukuyama (1995; cited in Doney et al., 1998, p.603) conceptualizes trust as "the expectation of regular, honest, and cooperative behavior based on commonly shared norms and values". Like Fukuyama (1995), Mayer et al (1995) focuses on expectations and defines trust as "the willingness of a person to be vulnerable to the actions of fellow coworkers whose behavior and actions that person cannot control." (p.709). Rather than focusing solely on one side, Donney et al (1998) provide more comprehensive definition such that trust reflects "willingness to rely on another party and to take action in circumstances where such action makes one vulnerable to the other party"( $p .604)$. Trust, in a way, refers to a positive expectation that another person will not act opportunistically through words, actions or decisions (Puusa \& Tolvanen, 2006).

Despite the abundance of trust definitions and increasing anticipation of its importance, trust has mostly been studied at a general level without acknowledging the different referents. However as Dirks and Skarlicki (2004) points out, identification of the different referents of trust such as organizational, supervisory or coworker trust enables organizations to better leverage the benefits of trust given the fact each type of trust has its own unique antecedents and consequences. In this study, we will focus on supervisory trust, which is argued to be different from organizational or coworker trust in terms of power differences and asymmetry of information. Adapting Mayer et al's (1995) definition of trust, we will conceptualize trust in supervisors as "the willingness of a person to be vulnerable to the actions of supervisors whose behavior and actions that person cannot control". In contrast to many studies adopting this definition, we will operationalize supervisory trust as a multi dimensional construct reflecting emotional / affective and cognitive side of interpersonal relations. In other words, following the suggestion of McAllister (1995), we will treat trust as "a single, super ordinate factor with cognitive and affective dimensions.

Cognition-based trust reflects the beliefs and judgments about other party's trustworthiness about fulfillments of prescribed responsibilities (Chen, Chen \& Meindl; 1998; Lewicki et al., 2006). As part of the professionalism, cognition-based trust provides both trustee and trustor with confidence that they will abide by their contract and treat each other equitably (Chen et al, 1998). Affect-based trust, on the other hand, represents emotional bond between trustee and trustor that goes beyond business or professional relationships. This type of trust manifests itself as personal care of and concern for others (Chen et al., 1998). Cognitive and affective dimensions of trust are argued to differ from each other based on interests. While affect-based trust has social side and relies on one's desire to be committed to the relationship and meet collective interests, cognition based trust has calculative-side and relies on one's desire to meet his/her self-interests. Although cognition and affect-based trust seem to represent the distinct dimensions, they are argued to reciprocally affect each other (Lewicki et al., 2006). Some researchers claim that cognition-based trust could evolve into affect-based trust because calculative and professional relationships may facilitate the development of more personalized and emotional relationships over time (Chen et., 1998). 


\subsection{The Relationship between Organizational Identification and Supervisory Trust}

Given the fact that trust is the basis of quality interpersonal relations, many researchers directed their attention to how trust permeates its effects on organizations and their members. Even though they have focused on different trust foci such as such as supervisory, coworkers or organizational trust, the researchers reached the same conclusion: Trust shapes variety of employee attitudes and behaviors such as job satisfaction, commitment, citizenship behavior and identification. Social Identity Theory (Tajfel, 1978), Social Exchange and Norm of Reciprocity (Gouldner, 1960; Blau, 1964) could shed light on how trust influences aforementioned attitudes and behaviors, including identification with the organization.

According to Social Identity Theory, individuals want to boost their self-esteem and worth by identifying themselves with trustworthy groups and organizations. Put in another way, defining themselves with reliable, honest and dependable organizations could help people portray to positive self-image to both themselves and other people. Compared to others, it would be easier for employees to identify with themselves with their organizations, whose actions and sayings are trustworthy. Similarly, if employees regard their supervisors as trustworthy, reliable and hones, they could feel sense of belongingness to the organization, which is represented and managed by these supervisors.

Social exchange theory, which is argued to provide conceptual underpinning of research on work attitudes and behaviors (Wayne, Shore \& Liden, 1997; cited in Aryee, Budhwar \& Chen, 2002), could also explain the relationship between trust and identification. The theory (Blau, 1964) claims that individuals feel obligation to treat other people favorably in exchange for a favorable treatment or reward they expect to receive. In a way, individuals create a "norm of reciprocity" in their relations, which leads them to show positive attitude and behavior in response to other individuals' constructive attitude and behaviors (Gouldner, 1960; Blau, 1964). The discretionary nature of when favors rendered will be reciprocated makes trust important parts of any exchange (Aryee et al., 2002). Following this corollary, norm of reciprocity and social exchanges within the organizations may force employees to reciprocate the favorable treatment of their supervisors with positive attitude and behaviors and increase their tendency to have trust in them. In other words, employees seem to respond supervisor's supportive behaviors and faith in them with the increased supervisory trust and the identification with organization.

Majority of the research focused on the antecedents and consequences of trust and identification, however they failed to integrate these two concepts and investigate their relations. Only the limited number of research (e.g., Edwards \& Cable, 2009; Restubog, 2008; Tuzun, 2006) investigated the effect of trust, especially the effect of organizational trust, on identification without taking into account different trust foci. For instance, Restubog et al. (2008) reported the mediating effect of organizational trust on the relationship between psychological contract breach and identification as significant, thereby demonstrated the positive linkage between trust and identification. Similarly, while testing the mediating effect of organization identification, Edwards and Cable (2009) found trust as an antecedent of identification, which in turn influences turnover intention.

Having the significant position power, managers usually shape the relation between organizations and employees (Van Knippenberg et al, 2007). Besides being a power-figure, managers are regarded as prototypes reflecting the characteristics of the organizations, therefore their attitudes and behaviors are usually generalized to overall organization. Employees trusting their supervisors could regard their organizations as trustworthy, thus feel themselves part of the organization and identify with it. Trust could also strengthen the bond between employees and managers, increase identification by developing collective feeling. In line with this, DeConnick (2011) reported positive relationship between supervisory trust and identification in a study conducted with sales people. Similarly, Tseng, Chen and Chen (2005) tested whether supervisory trust and reliability predict identification and reported positive and significant effects of both variables. Although testing the effect of supervisory trust, majority of the studies did not take the effects of different trust dimensions into account. To fill this gap, recently Erturk (2010) examined the moderating effects of trust in supervisor on the relationships among psychological empowerment, perceived organizational support (POS), and organizational identification. The researcher found both cognition and affect-based trust in supervisor to be strongly and positively associated with organizational identification. 
It is noteworthy to mention that the trust could also be an outcome rather than antecedent of identification. Employees feeling themselves part of their organization and sharing its values and beliefs could be more inclined to feel trust toward their supervisors. In fact, empirical studies (e.g., Puusa \& Tolvanen, 2006) suggested the existence of reciprocal relationship between trust and identification in which trust act as antecedent or consequence of identification. Although acknowledging the existence of reciprocal relationship, we still expect supervisor trust to predict identification because trust seems to encompass more general feelings than identification. Given the fact that the antecedents of identification (e.g., justice; perceived support) also predicted the trust, it is reasonable to expect both variables to be related to each other. We believe that employees are more likely to form bonds that foster identification when they trust their organizations, leaders and supervisors. Therefore, we propose that two distinct dimensions of trust (affective and cognition based trust) would positively predict organizational identification. In other words, employees perceiving their supervisors trustworthy both emotionally and cognitively are expected to feel more belongingness and oneness with the organization.

\section{H1a: Affect- based trust positively predicts organizational identification}

H1b: Cognition-based trust positively predicts organizational identification

Although both affect and cognition-based is expected to predict identification, gender may play a crucial role in this linkage. Trust and identification are related to perceptions shaped mostly by cognitive and affective processes. Since cognitive and affective processes are influenced by individual differences, it is reasonable to expect women and men to feel different levels of identification and trust in response to same organizational climate and managerial practices. According to Social Role Theory, women and men sometimes act differently because of the normative pressures forcing them to act consistent with gender typical roles and different skills acquired throughout the socialization process (Eagly \& Wood, 1991). The theory claims than women and men differ with respect to agentic versus communal tendencies. The gender role ascribed to women promotes communal behaviors, which stress processes and procedures. On the other hand, gender role ascribed to men promotes agentic behaviors, which stress outcomes and instrumentality (Bakan, 1966; cited in Buchan, Croson \& Solnick, 2008). Having agentic orientation, men are found to be more task-oriented and aggressive. Representing the other side, women seem to be more relationship oriented, display more empathy and emphasize harmony in their social interactions (Cross and Markus, 1993; cited in Buchan, Croson \& Solnick, 2008). Such differences could make women more sensitive to emotions, which led them to seek affect-based trust in their relations and make affect-based trust prominent in the development of identification. On the other hand, men's preference to use problem-focused coping strategies and task orientation could lead them to focus on calculative side of the relations, thereby seek cognition-based trust. Such a tendency could strengthen the effect of cognition-based trust on identification for male employees. This leads to our hypothesis:

$\mathrm{H} 2$ : The effect of affect-based trust on identification is stronger than that of cognition-based trust for women employees compared to men employees.

\section{DATA \& METHODOLOGY}

\subsection{Participants}

We collected data from the employees of a public organization in defense sector. During the data collection period, the total number of white collar employees was 389. Acknowledging the possibility of low response rate, we aimed to collect data from all employees. Although anonymity and confidentiality of the responses were ensured, we were able to obtain 170 questionnaires. Before proceeding with hypothesis testing, data from respondents (9 questionnaires) who had not evaluated more than $50 \%$ of the items were completely removed from analyses. For the remaining participants, missing values were replaced with mean values calculated for each variable. Total number of usable questionnaire turned out to be 161 questionnaires, constituting $41 \%$ response rate.

The sample comprised 79 females (49\%) and 82 males (51\%). Majority of participants were between 26 and 30 years of age (30.7\%) and between 31 and 35 years of age (28.7\%). Approximately $96 \%$ of the participants had 
bachelor or graduate degree, while only $4 \%$ had high school degree. $13 \%$ of the respondents had less than 1 , $\% 34$ had $1-5,16 \%$ had $6-10 ; 26 \%$ had $11-15$ year tenure; $6 \%$ had $16-20 ; 4 \%$ had more than 21 years tenure.

\subsection{Measures}

The questionnaire package consists of three sections. While the first section includes items about demographic variables such as sex, age and education, and tenure, the second and third sections compose of supervisory trust and organizational identification items respectively.

Supervisor Trust: Supervisor trust was measured with McAllister's Interpersonal Trust scale (1995). The original scale intends to measure affect and cognition based trust with 11-items. Cognition-based trust items (i.e., six items) measure one's rational assessment of the other party's trustworthiness (Sample item: "I can rely on this person not to make my job more difficult by careless work"), while affect-based trust items measure (i.e., five items) emotional bonds between another party (Sample item: "We have a sharing relationship. We can both freely share our ideas, feelings, and hopes"; McAllister, 1995). Responses to trust items were measured on a 5point scale format with " $1=$ Strongly Disagree to $5=$ Strongly Agree". Higher scores are indicative of higher cognition and affect based trust. The reliabilities of cognition-based trust $(\alpha=.85)$; and affect based trust ( $\alpha$ $=.77$ ) were found to be well above the criteria suggested by Nunnally (1978).

Organizational Identification: Riketta (2005:374) suggests researchers to use Mael and Ashforth's (1992) scale given the scale's widely accepted status in the field, its length and remarkably high validity and reliability figures obtained in various studies. Considering this suggestion, we used Mael and Ashforth's Orgaizational Identification scale, which measures employee's feelings of identification as a single dimension. Since Polat (2009) had translated the scale into Turkish and tested its validity, we used this translation without any alteration. In this six item scale, participants evaluated the items (e.g., "When someone criticizes my organization, it feels like a personal insult") using 5 point Likert type scale (1: Strongly Disagree, 5: Strongly Agree). Participants with higher scores were assumed to feel themselves as part of the organization. The internal consistency of the items was found be satisfactory in previous studies (e.g., Cronbach's $\alpha=.87$ in Mael \& Ashforth's study; Cronbach's $\alpha=.84$ in Polat's study) and in the current study (Cronbach's $\alpha=.84$ ).

\subsection{Analyses}

Hypothesis $1 \mathrm{a}$ and $1 \mathrm{~b}$ were tested with full latent variable modeling, which incorporates measurement and structural models at the same time. The measurement model was examined to determine whether the number of factors (i.e. affect-based trust, cognition-based trust and organizational identification) and the loadings of the questionnaire items were in line with the 3-factor structure. After examining factor structures, structural model part was assessed for testing hypothesized relations.

Hypothesis 2 was tested using multi-group structural analysis, which again includes both measurement and structural models .In multi group analysis, firstly measurement invariance, and then structural invariance needs to be established. While measurement invariance involves the test of whether instruments designed to measure aforementioned variables (i.e., trust dimensions and identification) were invariant, structural invariance involves the test of whether hypothesized relations were invariant across different samples. Following the suggestions of Jöreskog (1971), we firstly conducted baseline tests in which we examined the same model (including measurement and structural models) for women and men samples both separately and simultaneously. After these baseline tests, we made multi group analyses which involve the test of same model for women and men samples simultaneously, yet this time by imposing equality constraints. First factor loadings (Model 1), secondly structural weights (Model 2), thirdly structural covariances (Model 3), fourthly structural residuals (Model 4) and lastly measurement residuals (Model 5) were constrained to be equal across women and men samples. Nested model comparisons were made comparing the fit indices and analysis of chi square different differences for aforementioned 5 models.

In all analyses detailed above, maximum-likelihood-estimation was preferred given the adequacy of sample size and existence of normal distribution in the data (see, Tabachnick \& Fidell, 2001, p.697). AMOS 17 (Arbuckle, 2008), which enables the test of hypothesized relations and goodness of the model was utilized. The significance of hypothesized relations was assessed by examining the standardized estimates and t-values. 
Goodness of the model, that is whether the proposed model fit to the data, was examined through various statistics and indices (e.g., Chi Square / degrees of freedom, Comparative Fit Index (CFI), and Root Mean Square Error of Approximation (RMSEA)). Measuring the degree of similarity between observed covariance matrix and covariance matrix predicted by the model, chi-square value was desired to be insignificant. Given the fact that $\chi 2$ is sensitive to sample size, thereby turn out to be significant, most researchers prefer to take into account $\chi 2$ /df value (Schermelleh-Engel, Moosbrugger \& Müller, 2003). Accordingly, $x 2$ /df value between 0 and 2 is indicative of good fit and between 2 and 3 indicative of acceptable fit. For CFI, if the value is equal to .97 or above, this suggests the existence of good fit, whereas the value between .95 and .97 suggests acceptable fit (Schermelleh-Engel et al., 2003). As for RMSEA, value of less than .05 was considered evidence of a good fit, between .05 and .08 a fair fit, between .08 and .10 a mediocre fit, and greater than .10 a poor fit (MacCallum, Browne, \& Sugawara, 1996).

\section{FINDINGS \& DISCUSSIONS}

\subsection{Results of Preliminary Analyses}

Prior to analysis, organizational identification, affect and cognition-based trust were examined through various statistical programs for accuracy of data entry, missing values and normality. Missing values were replaced with mean values of respective items. No severe violations of univariate and multivariate normality were detected based on the results of Kolmogorov -Smirnov and Mardina coefficient tests (Kline, 2011). Before going further with path and multigroup analyses, we examined the variance inflation factor (VIF) and the condition index (Cl) to test multicollinearity. If VIF is larger than 10.0, it is regarded as an indication of multicollinearity (Kleinbaum, Lawrence, Muller, \& Nizam, 1998). In our study, VIFs ranged from 1.16 to 2.81, which were well below the threshold value. As for the other criterion, $\mathrm{Cl}$, values greater than 30 are accepted as the problem of collinearity (Tabachnick \& Fidell, 2001). Although the largest $\mathrm{Cl}$ was found to be very close to threshold value (i.e., 29.34), multicollinearity was not regarded as a pervasive problem considering VIF values.

\subsection{Results of Main Analyses}

After data screening, the measurement model was examined to see whether the items were able to measure organization identification, affective and cognition-based trust constructs. All items loaded satisfactorily on their respective constructs/factors, meaning, item and construct relations resulted as expected (see Table 1). After assessing measurement model, hypothesized relations were examined. According to the results, hypotheses $1 \mathrm{a}$ and $1 \mathrm{~b}$ were not supported. The path from cognition-trust to identification $(\beta=.30 ; p=.07)$ and the path from affective trust to identification $(\beta=.31 ; p=.07)$ were found to be insignificant; though close to the significance level. The covariance term indicated the existence of strong relationship between two dimensions of trust. After the examination of hypothesized relations, model fit was assessed using the criteria detailed in analysis section. The degree of fit between model and data was found to be acceptable, if not perfect. $(\mathrm{X} 2 / \mathrm{df}=2.14 ; \mathrm{RMSEA}=.08$ and $\mathrm{CFI}=.93)$

Table 1: Results of the Full-Latent Variable Analysis: Estimates

\begin{tabular}{lcccc}
\hline & $\begin{array}{c}\text { Unstandardized } \\
\text { Estimate }\end{array}$ & Standard Error & $\begin{array}{c}\text { Standardized } \\
\text { Estimates ( } \boldsymbol{\beta})\end{array}$ & $\mathbf{p}$ \\
\hline Affect-Based Trust & & & & .83 \\
AT1 & 1.04 & .10 & .87 & $<.001$ \\
AT2 & 1.10 & .10 & .87 & $<.001$ \\
AT3 & 1.14 & .11 & .78 & $<.001$ \\
AT4 & .85 & .09 & .71 & $<.001$ \\
AT5 & 1.00 & -- & & $<.001$ \\
Cognition-Based Trust & & & .82 & $<.001$ \\
CT1 & 1.01 & .08 & .88 & $<.001$ \\
CT2 & 1.07 & .08 & & \\
\hline
\end{tabular}




\begin{tabular}{lcccc}
\hline CT3 & .99 & .07 & .87 & $<.001$ \\
CT4 & 1.02 & .09 & .82 & $<.001$ \\
CT5 & 1.00 & -- & .81 & $<.001$ \\
CT6 & .66 & .09 & .54 & $<.001$ \\
Identification & & & & \\
ID1 & 1.00 & - & .58 & $<.001$ \\
ID2 & .70 & .15 & .42 & $<.001$ \\
ID3 & .85 & .13 & .62 & $<.001$ \\
ID4 & 1.22 & .16 & .84 & $<.001$ \\
ID5 & 1.44 & .18 & .88 & $<.001$ \\
ID6 & 1.18 & .17 & .68 & \\
Covariance & & & & \\
A.Trust-C.Trust & .54 & .09 & -- & $<.001$ \\
Paths & & & & \\
A.Trust >> Identification & .24 & .14 & .31 & .08 \\
C.Trust>>Identification & .24 & .14 & .30 & .07 \\
\hline
\end{tabular}

Considering the possibility of attenuation of effect sizes, which seems to be evidenced by strong covariance between two trust dimensions, we conducted multiple regression analysis that treat social desirability and demographics as controlling variables, cognition and affect-based trust as independent variables, identification as dependent variable. Unlike the results obtained from full-latent variable modeling, cognition based trust positively predicted the identification with the organization after controlling the effects of social desirability and demographic variables (see Table 2). The effect of affect-based trust, on the other hand, was found to be very close to significance level.

Tablo 2: Results of the Hierarchical Regression Analysis

\begin{tabular}{lccccc}
\hline & B & SE (B) & B & t & p \\
\hline Step 1 & & & & & \\
$\quad$ Gender & 1.50 & .64 & .19 & 2.33 & .02 \\
Age & -.07 & .28 & -.03 & -.26 & .79 \\
M.Status & .30 & .70 & .04 & .43 & .67 \\
\hline Step 2 & & & & & \\
$\quad$ Gender & 1.52 & .64 & .19 & 2.37 & .02 \\
Age & -.04 & .28 & -.01 & -.14 & .89 \\
Marital Status & .24 & .70 & .03 & .34 & .73 \\
$\quad$ S.Desirability & .20 & .24 & .09 & .82 & .41 \\
\hline Step 3 & & & & & \\
Gender & 1.01 & .55 & .14 & 2.04 & .05 \\
Age & -.10 & .24 & -.03 & -.43 & .66 \\
Marital Status & .57 & .60 & .07 & .95 & .34 \\
S.Desirability & .17 & .21 & .06 & .82 & .42 \\
Affect Trust & .20 & .10 & .22 & 1.94 & .05 \\
Cognition Trust & .28 & .09 & .34 & $2.92^{* *}$ & $.011^{* *}$ \\
\hline
\end{tabular}

Note-Gender: 1: Male; 2: Female; M.Status: 1: Married, 2: Single; S.Desirability is measured with 1: Right; 2: Wrong. B: Unstandardized Estimate; SE (B): Standard Error of unstandardized estimate; $\beta$ : Standardized Estimate.

To test the hypothesis 2, first baseline tests and then multi-group model tests were conducted. Within the framework of baseline tests, we tested the validity of hypothesized model first separately and then simultaneously for both samples. For both gender, three latent variables (i.e., affect based trust, cognitionbased trust and organizational identification) were hypothesized to be measured with 17 items and trust 
dimensions were assumed to predict organizational identification. Initial results indicated poor fitting model for both female $(X 2(117)=269.5, \mathrm{p}<.05 ; \mathrm{CFI}=.84 ; \mathrm{RMSEA}=.13)$ and male samples $(\mathrm{X} 2(117)=315.6, \mathrm{p}<.05 ; \mathrm{CFI}=$ .78 ; RMSEA $=.15$ ). The reason for poor fit was found to be related to lack of covariance terms among latent variables. Given the conceptual similarity of the constructs (albeit not same), it seemed theoretically logical to add the covariance terms for trust dimensions. After this modification, the model improved substantially for both female $(X 2(116)=189.4, p<.05 ; \mathrm{CFI}=.92 ; \mathrm{RMSEA}=.07)$ and male samples $(\mathrm{X} 2(116)=247.2, \mathrm{p}<.05 ; \mathrm{CFI}=$ .85 ; RMSEA $=.08$ ). These results indicated the similarity of factor structures for males and females. After checking the patterns of factor structure separately for each group, we tested the baseline model for both gender simultaneously and obtained acceptable model with $\chi 2 / \mathrm{df}=1.88 ; \mathrm{CFI}=.90 ; \mathrm{RMSEA}=.08$. Simultaneous (multigroup) test of baseline model yielded similar results with the separate tests such that all indicators /items were found to be significantly associated with their respective factors. After multi-group and single group baseline tests, we assessed the invariance of full constrained model. To assess invariance, we specified 5 different models in which all factor loadings, structural weights, structural covariances, structural residuals and measurement residuals were constrained to be equal across male and female samples. Firstly, the unconstrained model was compared with Model 1 in which all factor loadings were constrained to be equal across both samples. A $\chi 2$ difference test suggested the existence of measurement invariance across two samples $(\Delta \times 2(14)=9.89 ; p>.05)$. Once the measurement invariance model (Model 1$)$ was accepted, the more restrictive Model 2, in which both factor loadings and structural weights were constrained to be equal, was compared with Model 1 . Again, the $\chi 2$ difference test suggested the existence of invariance across two samples $(\Delta \times 2(2)=.24 ; p>.05)$. This result indicated the similarity of the hypothesized paths from trust dimensions to identification. In other words, the paths from cognition and affect based trust to identification were almost equal in magnitude for both samples. After demonstrating the hypothesized paths' invariance, the more restrictive Model 3 was specified. In Model 3, structural covariances between trust dimensions were assumed to be equal. Nested comparison of Model 3 and Model 2 yielded insignificant $\chi 2$ difference value, meaning that the magnitude of the relationship between affect and cognition-based trust did not differ across two samples $(\Delta \times 2(3)=5.77 ; p>.05$. Nested comparison of Model 3 and Model 4 , which constrains structural residuals to be equal again resulted in insignificant $\chi 2$ difference $(\Delta \times 2(1)=6.40 ; p>.05$, suggested the similarity of structural residuals for women and men samples. The last model comparison, however, yielded significant $\chi 2$ difference value $(\Delta \times 2(17)=69.48 ; p<.05$, suggesting that measurement residuals differed across two samples. After nested model comparisons, the fit between data and models was assessed using several indices. The fit between data and models deteriorated, as more restrictive models were utilized, but this deterioration was not considerable. The fit indices for Model 4, which suggested the existence of measurement, structural weights, structural covariance and structural residual invariances, indicated existence of an acceptable model (RMSEA = $.07 ; \mathrm{CFI}=.94 ; \chi 2 / \mathrm{df}=2.55$ ).

Looking at multi group analysis results (see Table 3), we concluded that the effects of cognition and affectbased trust on identification were similar in magnitude for women and men employees, which rendered Hypothesis 2 unsupported. Again, affect and cognition based trust could not predict the prevalence of organizational identification in both women (for affect-based trust, $\beta=.37, p>.05$; for cognition-based trust, $\beta$ $=.18, p>.05$ ) and men samples (for affect-based trust, $\beta=.42, p>.05$; for cognition-based trust, $\beta=.19, p>.05$ ). Remarkably, the relationship between two trust dimensions turned out to be strong for both men and women.

Table 3: Results of the Multi Group Analyses

\begin{tabular}{lllllllll}
\hline & \multicolumn{3}{c}{ Women } & & \multicolumn{2}{c}{ Men } \\
\hline & B & SE (b) & $\mathbf{( \beta )}$ & $\mathbf{p}$ & $\mathbf{B}$ & SE(b) & $\boldsymbol{\beta}$ & $\mathbf{p}$ \\
Affect-Based Trust & & & & & & & & \\
AT1 & 1.02 & .18 & .76 & $<.001$ & .99 & .13 & .86 & $<.001$ \\
AT2 & 1.17 & .19 & .87 & $<.001$ & 1.01 & .13 & .86 & $<.001$ \\
AT3 & 1.20 & .20 & .82 & $<.001$ & 1.06 & .13 & .90 & $<.001$ \\
AT4 & .92 & .17 & .75 & $<.001$ & .82 & .11 & .82 & $<.001$ \\
AT5 & 1.00 & -- & .65 & $<.001$ & 1.00 & -- & .75 & $<.001$ \\
\hline
\end{tabular}




\begin{tabular}{lllllllll}
\hline Cognition-Based Trust & & & & & & & \\
CT1 & 1.04 & .09 & .89 & $<.001$ & 1.02 & .15 & .76 & $<.001$ \\
CT2 & 1.04 & .08 & .94 & $<.001$ & 1.16 & .15 & .86 & $<.001$ \\
CT3 & .95 & .09 & .87 & $<.001$ & 1.11 & .14 & .88 & $<.001$ \\
CT4 & .95 & .010 & .76 & $<.001$ & 1.12 & .16 & .79 & $<.001$ \\
CT5 & 1.00 & -- & .87 & $<.001$ & 1.00 & -- & .76 & $<.001$ \\
CT6 & .66 & .12 & .58 & $<.001$ & .65 & .16 & .48 & $<.001$ \\
Identification & & & & & & & & \\
ID1 & 1.00 & -- & .77 & $<.001$ & 1.00 & -- & & $<.001$ \\
ID2 & .66 & .15 & .51 & $<.001$ & .71 & .26 & .52 & $<.001$ \\
ID3 & .59 & .12 & .57 & $<.001$ & .94 & .25 & .38 & $<.001$ \\
ID4 & .85 & .11 & .84 & $<.001$ & 1.35 & .31 & .61 & $<.001$ \\
ID5 & 1.10 & .12 & .92 & $<.001$ & 1.53 & .34 & .79 & $<.001$ \\
ID6 & .81 & .14 & .64 & $<.001$ & 1.51 & .36 & .72 & $<.001$ \\
Covariance & & & & & & & & \\
A.Trust-C.Trust & .44 & .11 & -- & $<.001$ & .58 & .14 &.- & $<.001$ \\
Paths & & & & & & & & \\
A.Trust >Identification & .46 & .38 & .37 & .22 & .25 & .15 & .42 & .09 \\
C.Trust>Identification & .20 & .32 & .18 & .53 & .14 & .17 & .19 & .42 \\
\hline
\end{tabular}

Note. B: Unstandardized Estimate; SE (B): Standard Error of unstandardized estimate; $\beta$ : Standardized Estimate.

\subsection{Discussion}

The primary purpose of this paper is to determine whether affect and cognition based trust affect the employee's propensity to identify themselves with their organizations. Additionally, the paper questions which type of trust, affect or cognition based, stronger predictor of organizational identification and whether the relationship between the dimensions of trust and organizational identification differs with respect to gender. The results of full-latent variable model failed to support the association between trust dimensions and organizational identification, although the results of traditional regression analyses suggested the opposite. The conflicting results could emanate from the strong relationship between affect and cognition-based trust. Although found to be distinct dimensions in previous studies (e.g., Holste \& Fields, 2005; Ng \& Chua, 2006; Webber \& Klimoski, 2004; Wilson, Straus, \& McEvily, 2006), in this study cognition and affect based trust was found to be strongly related to each other, which is evidenced by strong zero order correlation. This reciprocal relation seems to attenuate and render the effects of trust dimensions insignificant. As Grewal, Cote and Baumgartner (2004) state, the strong correlation between variables (i.e., trust dimensions) might have resulted in Type II error, which leads us not to detect significant relations (i.e., reject a false null hypothesis) (Banerjee, Chitnis, Jadhav, Bhawalkar, \& Chaudhury, 2009).

Looking at the results of traditional regression analysis, we can still claim that supervisory trust as a whole plays significant role in the development of identification. The voluminous literature on leadership has clearly demonstrated the influence of supervisors on employees (e.g., Bass, Avalio, \& Pointon,1990). Through critical decisions such as pay raises, promotions, demotions, and training opportunities that affect employees, supervisors have a potential to shape work environment, set the tone for interpersonal relationships and influence employee's attitude toward organization and their coworkers. While attaching utmost importance to the messages of supervisors (Levinson, 1965; Liden, Bauer, \& Erdogan, 2004), employees usually regard supervisors' attitudes as the representation of the organization's attitudes. As the Social Identity Theory suggests, individuals want to boost their self-esteem and worth by identifying themselves with trustworthy groups, organizations and people. When employees see their supervisors trustworthy, dependable, and reliable, they tend to feel belongingness to their organizations (e.g., DeConninck 2001; Erturk, 2006). Besides, norm of reciprocity and social exchanges within the organizations may force employees to reciprocate the favorable treatment of supervisors with positive attitude and behaviors (Blau, 1964). Supervisor's supportive behaviors seem to be reciprocated with the increased supervisory trust and the identification with organization. 
Our data failed to support the main thrust of the study, that gender affects the linkage between supervisory trust and identification. The study's findings show that male and female employees have similar patterns regarding the effect of affect and cognition-based trust on identification. This result seems to be consistent with Riordan and Shore's (1997) argument, which indicates that much of differences in work attitudes are due to situational factors rather than gender per se. As Lefkowitz (1994) found that when the effects of systematic differences in the jobs held and the rewards received by women as compared with men were controlled, there could be no differences between men and women in their responses to work. In this study, women and men employees have white collar jobs having similar characteristics in terms of gender segregation of the work responsibilities and rewards. We believe that lack of differences regarding the effect of trust on identification could be explained with the similar situational factors affecting women and men employees.

The study has some conceptual and methodological limitations, which should be acknowledged while interpreting the findings and giving advice for future research. Conceptually, the nature and number of variables included in this study provided limited perspective regarding the development of organizational identification. Our article centers on the influence of only affect and cognition-based trust on the development of organizational identification although one's level of identification may be influenced by variety of organizational, relational, or individual factors (Doney \& Cannon, 1997; McAllister, 1995). We suggest researchers to investigate the effects of individual and organizational level variables such as propensity to trust and organizational culture in order to provide more comprehensive perspective regarding organizational identification. For example future research may integrate personality theories to identification and trust literatures to better understand why trust in organizations, supervisors or coworkers do not have similar power on identification for different employees. This study examined only the direct effects. However, moderators that could affect the relationship between identification and trust are also conceivable.

Since this study focused only on supervisor trust, its findings have limited generalizability to other types of trust, namely coworker or organizational trust, which could be shaped by more calculative factors like reward structures and appraisal procedures or affective factors like friendship. Therefore we suggest researchers to examine the same hypotheses for different referents of trust such as coworker, organization and subordinates. Furthermore, although no evidence was found as to the effect of demographics on the hypothesized relationships, it should be acknowledged that the variables may not operate identically in all contexts, thereby cast doubt about the generalizability of the results.

As indicated above, the study has methodological limitations as well. The data of this research relied on selfreports of the employees. Given the fact that people have a better access to intrapsychic information such as thoughts, feelings and sensations that are unavailable to other people (Robins, Norem, \& Cheek, 1999; cited in Paulhus \& Vazire, 2007), we thought that other sources (i.e., supervisor or peer reports) or techniques (i.e., experimental designs) might not provide the detailed information about employees' feelings of trust and identification. In other words, we preferred self-report technique because of easy interpretability and sheer practicality. However, the use of purely self-reporting casts doubts about the validity of the results. As Paulhus and Vazire (2007) point out, this technique suffers from many measurement artifacts and credibility-related problems. Motives like consistency seeking, self-enhancement and self-presentation could affect people's ability and desire to report their actual feelings and thoughts. Apart from these motives, responses could be affected by many factors that have not been anticipated and controlled in this study. For example people may differ from each other with respect to their propensity to trust-a personality trait which could influence their perceptions regarding dyadic relations. Besides that, although Harman's one-factor test (Podsakoff \& Organ, 1986) and multi-group confirmatory factor analysis demonstrated the distinctiveness of the constructs, collecting single source data with self-report methodology might still cause common method variance problem. As shown by Spector (1987), the impact of common method variance on self-report measures of affective and perceptual constructs was found to be mediocre, if not zero. This problem could have inflated the correlations between variables and result in spurious results. Several remedies such as data collection from different sources at different times could have taken to rule out this problem and increase the validity of the results. The current study is a promising beginning; future research might be enriched with measures complementary to self-reports. 
Other limitation may arise from strong associations among several antecedents. Although there is no sign of multi-collinearity or singularity among variables, strong associations among trust dimensions made it difficult to disentangle their impact on organization identification. As indicated before, high correlation between affect and cognition based trust could have attenuated the impact of these trust dimensions on organizational identification. Therefore, we suggest researchers to examine the impact of overall supervisory trust on identification, in addition to the impact of different trust dimensions.

The last methodological limitation is related to relatively low response rate. Although Visser, Krosnick, Marquette and Curtin (1996) demonstrated that surveys with low response were not necessarily low in validity, we still acknowledge that low response rates could cast doubts about the validity of the results. Therefore we suggest researchers to obtain data from samples having comparable characteristics, yet with high response rates.

\section{CONCLUSION}

Given their effects on absenteeism, turnover, and job dissatisfaction, planned interventions should be designed to boost both trust and identification within the organization. Organizations with high levels of internal trust are argued to be more successful, adaptive and innovative than organizations with low level of trust or characterized with distrust (Shockley-Zalabak, Ellis, \& Winogrard, 2000). Trust in organization and a supervisor is associated with number of positive individual and organizational outcomes such as enhanced teamwork, collaboration, employee satisfaction and commitment. Therefore it becomes imperative to understand the antecedents or predictors of trust and boost the level of trust within the organization. Results of the current investigation demonstrate the powerful role of supervisory trust in the formation of employees' attitudes such as employee's identification with the organization. As Mayer et al. (1995) points out, demonstrating the integrity, ability and benevolence of supervisors could enhance trustworthiness of supervisors in the eyes of subordinates. Also good treatment by the supervisors could create obligation in employees that they should treat their supervisors well in return. If the supervisors act fairly when allocating the rewards and resources, communicate with employees in a constructive way, and show genuine interest toward the interest of employees, they could build both cognition and affect based trust, which in turn could enhance identification. We believe that managers / supervisors could contribute the success of their organization through the selection of other managers and employees who possess talent to build an environment that fosters organizational identification.

Despite the aforementioned limitations, we hope that this study contributed to existing knowledge by examining the role of supervisory trust on the development of identification with the organization. Based on the results, we suggest both practitioners and researchers to treat affect and cognition based trust as two important, even indistinguishable components of overall feelings of trust that could boost employee's level of identification. 


\section{REFERENCES}

Arbuckle, J. 2008, “Amos 17.0 user's guide”. Spring House, PA: AMOS Development Corporation.

Aryee, S., Budhwar, P. S. \& Chen, Z. X. 2002, "Trust as a mediator of the relationship between organizational justice and work outcomes: Test of a social exchange model", Journal of Organizational Behavior, Vol. 23, no.3, pp.267-285.

Ashforth, B. E. \& Mael, F. 1989, "Social identity theory and the organization”, Academy of Management Review, Vol. 14, no.1, pp. 20-39.

Axelrod, R. 1984, "The evolution of cooperation". New York: Basic Books.

Banerjee, A., Chitnis, U. B., Jadhav, S. L., Bhawalkar, J. S. \& Chaudhury, S. 2009, "Hypothesis testing, type I and type II errors", Industrial Psychiatry Journal, Vol.18, no.2, pp.127-131

Bass, B. M., Avolio, B. J. \& Pointon, J. 1990, "The implications of transactional and transformational leadership for individual, team, and organizational development". Research in Organizational Change and Development, Vol.4, pp.231-272.

Blau, P. M. 1964, "Exchange and power in social life". New York: Wiley.

Buchan, N. R., Croson, R. T. \& Solnick, S. 2008, "Trust and gender: An examination of behavior and beliefs in the Investment Game", Journal of Economic Behavior \& Organization, Vol. 68, no.3, pp. 466-476.

Chen, C. C., Chen, X. P. \& Meindl, J. R. 1998, "How can cooperation be fostered? The cultural effects of individualism-collectivism", Academy of Management Review, Vol.23, no.2, pp. 285-304.

Davis, J. H., Schoorman, F. D., Mayer, R. C. \& Tan, H. H. 2000, "The trusted general manager and business unit performance: Empirical evidence of a competitive advantage", Strategic Management Journal, Vol. 21, no.5, pp.563-576.

Deaux, K. 1996, "Social Identification". Higgins, Edward Tory (Ed); Kruglanski, Arie W. (Ed), (1996). Social psychology: Handbook of basic principles. , (pp. 777-798). New York, NY, US: Guilford Press, x, 948 pp.

DeConinck, J. B. 2011, "The effects of ethical climate on organizational identification, supervisory trust, and turnover among salespeople", Journal of Business Research, Vol. 64, no.6, pp. 617-624.

Deutsch, M. 1962, "Cooperation and trust: Some theoretical notes". Nebraska Symposium on Motivation, 1962. , (pp. 275-320). Oxford, England: Univer. Nebraska Press, xiii, 330.

Dirks, K. T. 2000, "Trust in leadership and team performance: Evidence from NCAA basketball”, Journal of applied psychology, Vol. 85, no. 6, 1004-1012.

Dirks, K. T. \& Ferrin, D. L. 2001, "The role of trust in organizational settings”. Organization Science, Vol. 12, no.4, $450-467$.

Dirks, K. T. \& Skarlicki, D. P. 2004, "Trust in leaders: Existing research and emerging issues", Trust and distrust in organizations: Dilemmas and approaches, Vol.7, pp. 21-40.

Doney, P. M., Cannon, J. P. \& Mullen, M. R. 1998, “Understanding the influence of national culture on the development of trust". Academy of Management Review, Vol.23, no.3, pp. 601-620.

Dutton, J. E., Dukerich, J. M. \& Harquail, C. V. 1994, “Organizational images and member identification”. Administrative Science Quarterly, Vol.39, no.2, pp. 239-263.

Eagly, A. H. \& Wood, W. 1991. "Explaining sex differences in social behavior: A meta-analytic perspective". Personality and Social Psychology Bulletin, Vol.17, no.3, pp. 306-315.

Edwards, J. R. \& Cable, D. M. 2009, "The value of value congruence", Journal of Applied Psychology, Vol. 94, no.3, pp.654-677.

Ertürk, A. 2010, "Exploring predictors of organizational identification: Moderating role of trust on the associations between empowerment, organizational support, and identification", European Journal of Work and Organizational Psychology, Vol.19, no.4, pp.409-441.

Fukuyama, F. 1995, "Trust: The social virtues and the creation of prosperity". New York, NY: The Free Press.

Gouldner, A. W. 1960, "The norm of reciprocity: A preliminary statement", American Sociological Review, Vol. 25, pp. 161-178.

Grewal, R., Cote, J. A. \& Baumgartner, H. 2004, "Multicollinearity and measurement error in structural equation models: Implications for theory testing", Marketing Science, Vol.23, no.4, pp. 519-529.

Hall, D. T., Schneider, B. \& Nygren, H. T. 1970, “Personal factors in organizational identification”. Administrative Science Quarterly, Vol. 15, no.2. pp. $176-190$

Hofstede, G. 1980. "Culture's Consequences", Beverly Hills, CA: Sage Publications.

Holste, J. S. \& Fields, D. 2005, August, "The Relationship of Affect and Cognition Based Trust with Sharing and Use of Tacit Knowledge", In Academy of Best Management Proceedings (Vol. 2005, No. 1, pp. B1-B6).

Jöreskog, K. G. 1971, "Simultaneous factor analysis in several populations". Psychometrika, Vol.36, no.4, pp. 409-426. 
Kelman, H.C. 1961, "Processes of opinion change”, Public Opinion Quarterly, Vol.25, pp. 57-78.

Kleinbaum, D. G., Lawrence, L. L., Muller, K. E. \& Nizam, A. 1998, “Applied regression analysis and other multivariable methods” (3rd ed.). New York: Duxbury.

Kreiner, G. E. \& Ashforth, B. E. 2004, "Evidence toward an expanded model of organizational identification", Journal of Organizational Behavior, Vol 25, no.1, pp. 1-27.

Lefkowitz, J. 1994, "Sex-related differences in job attitudes and dispositional variables: Now you see them,...." Academy of Management Journal, Vol. 37, no. 2, pp. 323-349.

Levinson, H. 1965, “Reciprocation: The relationship between man and organization”, Administrative Science Quarterly, Vol.9, no.4, pp. 370390 .

Lewicki, R. J., Tomlinson, E. C. \& Gillespie, N. 2006, “Models of interpersonal trust development: Theoretical approaches, empirical evidence, and future directions". Journal of Management, Vol 32, no.6, pp. 991-1022.

Liden, R. C., Bauer, T. N., \& Erdogan, B. 2004. "The role of leader-member exchange in the forming and dynamic relationship between employee and employer". In J. Coyle-Shapiro, L. Shore, S. Taylor, \& L. Tetrick (Eds.). The Employment Relationship: Examining Psychological and Contextual Perspectives. (pp. 226-250). Oxford University Press.

MacCallum, R. C., Browne, M. W. \& Sugawara, H. M. 1996, "Power analysis and determination of sample size for covariance structure modeling", Psychological Methods, Vol.1, no.2, pp.130-149.

Mael, F. \& Ashforth, B. E. 1992, "Alumni and their alma mater: A partial test of the reformulated model of organizational identification", Journal of Organizational Behavior, Vol. 13, no.2, pp. 103-123.

Mael, F. A. \& Ashforth, B. E. 2001, "Identification in work, war, sports, and religion: Contrasting the benefits and risks". Journal for the Theory of Social Behaviour, Vol.31, no.2, pp. 197-222.

Mayer, R. C., Davis, J. H. \& Schoorman, F. D. 1995, “An integrative model of organizational trust”. Academy of Management Review, Vol. 20, no.3, pp. 709-734.

McAllister, D. J. 1995, "Affect-and cognition-based trust as foundations for interpersonal cooperation in organizations". Academy of Management Journal, Vol. 38, no.1, pp.24-59.

Mulki, J. P., Jaramillo, F. \& Locander, W. B. 2006, "Effects of ethical climate and supervisory trust on salesperson's job attitudes and intentions to quit", Journal of Personal Selling \& Sales Management, Vol. 26, no.1, pp.19-26.

Ng, K. Y. \& Chua, R. Y. 2006, "Do I contribute more when I trust more? Differential effects of cognition-and affect-based trust", Management and Organization Review, Vol 2, no.1, pp. 43-66.

Nunnally, J. 1978. "Psychometric methods". New York: McGraw Hill.

O'Reilly, C. A. \& Chatman, J. 1986, "Organizational commitment and psychological attachment: The effects of compliance, identification, and internalization on prosocial behavior", Journal of Applied Psychology, Vol.71, no.3, pp.492-499.

Paulhus, D. L., \& Vazire, S. 2007, "The self-report method". In R. W. Robins, R. C. Fraley, and R. Krueger (Eds.), Handbook of Research Methods in Personality Psychology (pp. 224-239). New York: Guilford Press.

Podsakoff, P. M. \& Organ, D. W. 1986, "Self-reports in organizational research: Problems and prospects, Journal of management", Vol. 12, no.4, pp. 531-544.

Polat, M. 2009, “Örgütsel özdeşleşmenin öncülleri ve ardılları üzerine bir saha araştırması”. [A field study about the antecedents and consequences of organizational identification], Doktora tezi [Unpublished PhD Thesis]. Bursa: Uludağ Universitesi Sosyal Bilimleri Enstitüsü.

Pratt, M. G. 1998, "Central Questions in Organizational Identification”. Whetten, David A. (Ed); Godfrey, Paul C. (Ed), (1998). Identity in organizations: Building theory through conversations. Foundations for organizational science., (pp. 171-207). Thousand Oaks, CA, US: Sage Publications, Inc, xi, $308 \mathrm{pp}$.

Puusa, A. \& Tolvanen, U. 2006, "Organizational identity and trust", EJBO Electronic Journal of Business Ethics and Organization Studies, Vol. 11, no.2, Retrieved from http://ejbo.jyu.fi.

Restubog, S.L.D., Hornsey, M.J., Bordia, P. \& Esposo, S.R. 2008, "Effects of psychological contract breach on organizational citizenship behavior: Insights from the group value model”, Journal of Management Studies, Vol. 45, no. 8, pp. 1377-1400.

Riketta, M. 2005. “Organizational identification: A meta-analysis”, Journal of Vocational Behavior, Vol. 66, no.2, pp. 358-384.

Riordan, C. M. \& Shore, L. M. 1997, “Demographic diversity and employee attitudes: An empirical examination of relational demography within work units", Journal of Applied Psychology, Vol. 82, no.3, pp. 342-358.

Schermelleh-Engel, K., Moosbrugger, H. \& Müller, H. 2003, "Evaluating the fit of structural equation models: Tests of significance and descriptive goodness-of-fit measures", Methods of Psychological Research Online, Vol. 8, no. 2, pp. 23-74. 
Shockley-Zalabak, P., Ellis, K. \& Winograd, G. 2000, "Organizational trust: What it means, why it matters", Organization Development Journal, Vol. 18, No.4, pp.35-48.

Spector, P. E. 1987, "Method variance as an artifact in self-reported affect and perceptions at work: Myth or significant problem?", Journal of Applied Psychology, Vol. 72, no.3, pp.438-443.

Stengel, M. 1987, "Identifikationsbereitschaft, Identifikation, Verbundenheit mit einer Organisation oder ihren Zielen" [Readiness for identification, identification with, and commitment to, an organization or its goals]. Zeitschrift fuer Arbeits- und Organisationspsychologie, Vol. 31, pp. 152-166

Tabachnick, B. G., \& Fidell, L. S. 2001, “Using multivariate statistics”. Needham Heights, Massachusetts: Allyn and Bacon.

Tajfel, H. E. 1978, "Differentiation between social groups: Studies in the social psychology of intergroup relations". London: Academic Press.

Tseng, H. C., Chen, T. F. \& Chen, F. I. 2005, “Constructing and testing a model of trustworthiness, trust behavior and organizational identification". Journal of Nursing Research, Vol.13, no.4, pp. 293-304.

Tüzün, i. K. 2006, "Örgütsel güven, örgütsel kimlik ve örgütsel özdeslesme iliskisi: uygulamali bir çalisma” (An empirical research on the relationships between organizational trust, organizational identity and organizational identification).Unpublished PhD Thesis

Van Knippenberg, D., Van Dick, R. \& Tavares, S. 2007, "Social identity and social exchange: Identification, support, and withdrawal from the job", Journal of Applied Social Psychology, Vol. 37, no.3, pp. 457-477.

Visser, P. S., Krosnick, J. A., Marquette, J. \& Curtin, M. (1996), "Mail surveys for election forecasting? An evaluation of the Columbus Dispatch poll", Public Opinion Quarterly, Vol. 60, no.2, pp. 181-227.

Webber, S. S. \& Klimoski, R. J. 2004, “Client-project manager engagements, trust, and loyalty”, Journal of Organizational Behavior, Vol. 25, no.8, pp. 997-1013.

Wilson, J. M., Straus, S. G. \& McEvily, B. 2006, "All in due time: The development of trust in computer-mediated and face-to-face teams", Organizational Behavior and Human Decision Processes, Vol. 99, no.1, pp. 16-33. 